\title{
Finite Element Analysis of Composite Laminated Beams using ANSYS
}

\author{
S.H. Nagarajanayaka and Dr.R.J. Fernandes
}

\begin{abstract}
Laminated composite materials find numerous applications in aerospace, military and automotive industries, due to their low specific weight (mass), high specific strength and stiffness.But, they are highly susceptible to the external loadings which can affect its gross performance. Therefore it is necessary to study the structural behavior of laminated beams such as deflections and stresses.
\end{abstract}

In this paper, finite element analysis have been carried out usingFEM software(Ansys15.0) for various length-to thickness ratios, modulus ratio and different ply orientation for diffrent boundary conditions to study the effect of transverse shear deformation on deflection of laminated composite beams.

Keywords--- Laminated Composite Beam, HingedHinged $(H-H)$ and Hinged-Clamped $(H-C)$ Clamed-Clamed (Cc) Boundary Conditions, Finite Element Method (FEM), Ansys 15.0

\section{INTRODUCTION}

$\mathrm{L}$ AMINATED composite materials are increasingly being used in a large variety of structures including aerospace, marine and civil infrastructure owing to the many advantages they offer: high strength/stiffness for lower weight, superior fatigue response characteristics, facility to vary fiber orientation, material and stacking pattern, resistance to electrochemical corrosion, and othersuperior material properties of composites. At the same time, the fabricated material poses new problems, such as failure due to delamination and pronounced transverse shear effects due to the high ratio of in-plane modulus to transverse shear modulus.Composite beams are Light weight structures that can be found in many various applications including aerospace, submarine, medical equipment, automotive and construction industries. Buildings, steel framed structures and bridges are examples of beam applications in civil engineering.

Composite materials are those formed by combining two or more materials on a macroscopic scale such that they have better engineering properties than the conventional materials, for example metals. It is also defined as s material system which consist of a mixture or a combination of two or more distinctly differing materials which are insoluble in each other and differ in form or chemical composition. Some of the properties that can be improved by forming a composite

S.H. Nagarajanayaka, PG Student, Department of Civil Engineering, SDM College of Enginering and Technology, Dharwad, India. E-mail:nagaraj.hrm@gmail.com

Dr.R.J. Fernandes, Assistant Professor, Department of Civil Engineering SDMCET, Dharwad, India.E-mail:fernandes.regi@gmail.com DOI:10.9756/BIJMMI.8177 material are stiffness, strength, weight reduction, corrosion resistance, thermal properties, fatigue life, and wear resistance.

\section{A. Objective of the Present Work}

The objective of the present work is to analyse the laminated composite beam using FEM software(Ansys 15.0) and to conduct the parametric study on response of laminated composite beam under static loading.

\section{B. Methodology}

- The Finite Element model is prepared in ANSYS.15.0 software for analysis purpose.

- The study on displacement parameter is done using Ansys.15.0 software for various length to thickness ratios, and different ply orientation varying number of laminas for Static loading condition.

- The material selected for parametric study is orthotropic in nature.

- Results obtained from ANSYS software are tabulated and compared with selected journal papers.

- Based on above observations, the results, discussions and conclusions will be presented.

\section{LITERATURE REVIEW}

A.A.Khdeir and J.N.Reddy [1] They are carried out state-space concept in combination with the Jordan canonical form is presented to solve the governing equations for the bending of cross-ply laminated composite beams. The classical, first-order, 2nd-order and 3rd-order theories were used in the analysis. Exact solutions have been developed for symmetric and anti-symmetric cross-ply beams with arbitrary boundry condition subjected to arbitrary loadings.

T.Kant and B.S.Manjunath [2]: they are usedRefined higher-order displacement models for the behaviour of symmetric and unsymmetric laminated composite beams based on $\mathrm{C}^{0}$ finite element discretization. The discrete element considered is a four-noded cubic with kinematic models having three, four and five degrees of freedom per node. The computer program developed incorporates the realistic prediction of inter-laminar stresses from equilibrium equations. Results are compared with the elasticity solutions, show excellent agreement.

Dipak.Kr. Maiti and P.K.Sinha [3]: In this study they are investigation a higher-order shear deformation theory and the conventional first-order theory are used to develop a finite element method to analyse accurately the bending and free vibration behaviour of laminated composite beams, using nine-nodedisoparametric elements. The higher-order theory assumes all the displacement components, $\mathrm{u}, \mathrm{v}$ and $\mathrm{w}$, which contain variation up to a cubic power of z. The effects of various parameters such as fibre orientation, stacking 
sequence, span-to-thickness ratio and support condition on the non-dimensionalised deflections, stresses and fundamental frequencies are investigated. Cases where only the higherorder theory is likely to yield accurate results are highlighted

B. Sidda Reddy, A. Ramanjaneya Reddy, J. Suresh Kumar And K. Vijaya Kumar Reddy[4]: For laminated plate a number of finite element analyses have been carried out for various side-to-thickness ratios, aspect ratios andmodulus ratios to study the effect of transverse shear deformation on deflection and stresses of laminated composite plates subjected to uniformly distributed load. They found that on the deflections and stresses, the effect of coupling is to decrease the deflections with the increase in the aspect ratio and modulus ratio and increase the stresses with the increase in the side-to-thickness ratio and modulus ratio.

\section{FinITE ELEMENT ForMULATION}

In FEM, the physical domain is divided into number of sub-domains, which are termed as finite elements. This process of dividing is called discretisation which represents the complex domain in a proper representation. The number of these finite elements decides the accuracy of the solution. Increase in finite element numbers increases the accuracy but requires more computational effort and time. So it has to be appropriately selected by considering the past experience of the analyst and after making the convergence study by varying mesh size.

In the standard finite element technique, the total solution domain is discretized into NE sub domains (elements), such that

$$
\Pi(\delta)=\sum_{e=1}^{N E} \Pi^{e}(\delta)
$$

The potential energy for an element is given by

$$
\Pi^{e}(\delta)=U^{e}-W^{e},
$$

Where $\delta$ is the vector of unknown displacement variable, then the displacement vector ${ }^{\text {within }}{ }^{\text {the }}$ element is discretized such that

$$
\delta=\sum_{i=1}^{N N} N_{i} \delta_{i}
$$

where $\mathrm{NN}$ is the number of nodes in an element and generalized strain at any point given by

$$
\bar{\varepsilon}=\sum_{i=1}^{N N} B_{i} \delta_{i},
$$

The $\mathrm{B}$ matrix has a dimension of $3 \times 3$, in which the nonzero elements are

$$
[B]=\left[\begin{array}{ccc}
\frac{\partial N_{i}}{\partial x} & 0 & 0 \\
0 & 0 & \frac{\partial N_{i}}{\partial x} \\
0 & \frac{\partial N_{i}}{\partial x} & N_{i}
\end{array}\right]
$$

Element stiffness matrix can be computed by using the fallowing relation

$$
K_{i j}^{e}=b \int_{-1}^{1} B_{i}^{t} D B_{j}|J| d \xi
$$

The consistent load vector, due to uniformly distributed transverse load q can be written as

$$
\mathrm{p}_{i}=\int_{-1}^{1} N_{i}^{t} q|J| d \xi
$$

The above equation is evaluated numerically using the four Gauss quadrature rule. The result is

$$
\mathrm{p}_{i}=\sum_{a=1}^{g} W_{a} N_{i}^{t}(0, q, 0)|J| d \xi
$$

Where ${ }^{|J|}$ is the Jacobian conversion.

\section{RESULTS AND DisCUSSIONS}

The finite element commercial package ANSYS 15.0 hasbeen used for the finite element analysis using ANSYSSHELL 8node 281 element in the modeling.

composite laminated beam is subject to transverse distributed load with various boundary condition has been

\begin{tabular}{|c|c|c|}
\hline $\mathrm{w}$ & $\mathrm{N}$ & $\mathrm{w}=\mathrm{w} \times \mathrm{n}$ \\
\hline $\begin{array}{l}\text { Max. } \\
\text { displacement }\end{array}$ & $\begin{array}{l}\left(100 \times E_{2} \times h^{3}\right) /(q \times \\
\left.L^{4}\right)\end{array}$ & $\begin{array}{l}\text { Non } \\
\text { dimensional }\end{array}$ \\
\hline
\end{tabular}
considered for the present study. All laminae are assumed to be same thickness and made of the same orthotropic material.

For the validation and analysis work, the material used has following properties.

Table 1: Material Properties

\begin{tabular}{|c|c|c|}
\hline Properties & Values & Units \\
\hline $\mathrm{E}_{1}=$ & 25 & $\mathrm{Gpa}$ \\
\hline $\mathrm{E}_{2}=$ & 1 & $\mathrm{Gpa}$ \\
\hline $\mathrm{E}_{3}=$ & 1 & $\mathrm{Gpa}$ \\
\hline $\mathrm{G}_{12}=$ & 0.5 & $\mathrm{Gpa}$ \\
\hline $\mathrm{G}_{13}=$ & 0.5 & $\mathrm{Gpa}$ \\
\hline $\mathrm{G}_{23}=$ & 0.2 & $\mathrm{Gpa}$ \\
\hline$\mu_{12}=$ & 0.25 & - \\
\hline$\mu_{23}=$ & 0.25 & - \\
\hline$\mu_{13}=$ & 0.25 & - \\
\hline $\mathrm{q}_{\mathrm{o}}=$ & 1 & $\mathrm{~N} / \mathrm{sqm}$ \\
\hline
\end{tabular}

All the output values for displacement are converted into non-dimensional form by multiplying with term ' $n$ '. 


\section{A. Validation}

For data validation, the non dimensional displacement values from ANSYS software are compared with standard values from A.A.Khdeir And J.N.Reddy [1] and percentage variation is calculated. From the comparison, we can see that errors are negligible and Hence we can go for parametric study for various boundary condition.

Table 2: Validation of Non Dimensional Displacement for Hnged-Hinged Beam

\begin{tabular}{|l|l|l|l|l|}
\hline \multicolumn{5}{|l|}{ Validation for non dimensional displacement } \\
\hline $\begin{array}{l}\text { Fiber } \\
\text { orientation }\end{array}$ & L/h & $\begin{array}{l}\text { A.A.Khdeir and } \\
\text { J.N.Reddy[1] }\end{array}$ & ANSYS & $\begin{array}{l}\% \\
\text { error }\end{array}$ \\
\hline $0 / 90 / 0$ & 5 & 2.41 & 2.65 & $-10 \%$ \\
\hline $0 / 90 / 0$ & 10 & 1.10 & 1.15 & $-5 \%$ \\
\hline $0 / 90 / 0$ & 50 & 0.67 & 0.67 & $0 \%$ \\
\hline
\end{tabular}

Table 3: Validation of Non Dimensional Displacement for Clamped-Clamped Beam

\begin{tabular}{|l|l|l|l|l|}
\hline \multicolumn{5}{|l|}{ Validation for non dimensional displacement } \\
\hline $\begin{array}{l}\text { Fiber } \\
\text { orientati } \\
\text { on }\end{array}$ & $\begin{array}{l}\text { L/ } \\
\text { h }\end{array}$ & $\begin{array}{l}\text { A.A.Khdeir } \\
\text { and } \\
\text { J.N.Reddy[1] }\end{array}$ & ANSYS & \% error \\
\hline $0 / 90 / 0$ & 5 & 1.63 & 2.12 & $-30 \%$ \\
\hline $0 / 90 / 0$ & 10 & 0.53 & 0.63 & $-18 \%$ \\
\hline $0 / 90 / 0$ & 50 & 0.15 & 0.15 & $-2 \%$ \\
\hline
\end{tabular}

Table 4: Validation of Non Dimensional Displacement for Clamped-Hinged Beam

\begin{tabular}{|l|l|l|l|l|}
\hline \multicolumn{5}{|l|}{ Validation for non dimensional displacement } \\
\hline $\begin{array}{l}\text { Fiber } \\
\text { orientation }\end{array}$ & L/h & $\begin{array}{l}\text { A.A.Khdeir and } \\
\text { J.N.Reddy[1] }\end{array}$ & ANSYS & $\begin{array}{l}\% \\
\text { error }\end{array}$ \\
\hline $0 / 90 / 0$ & 5 & 1.95 & 2.45 & $-25 \%$ \\
\hline $0 / 90 / 0$ & 10 & 0.74 & 0.83 & $-13 \%$ \\
\hline $0 / 90 / 0$ & 50 & 0.28 & 0.29 & $-4 \%$ \\
\hline
\end{tabular}

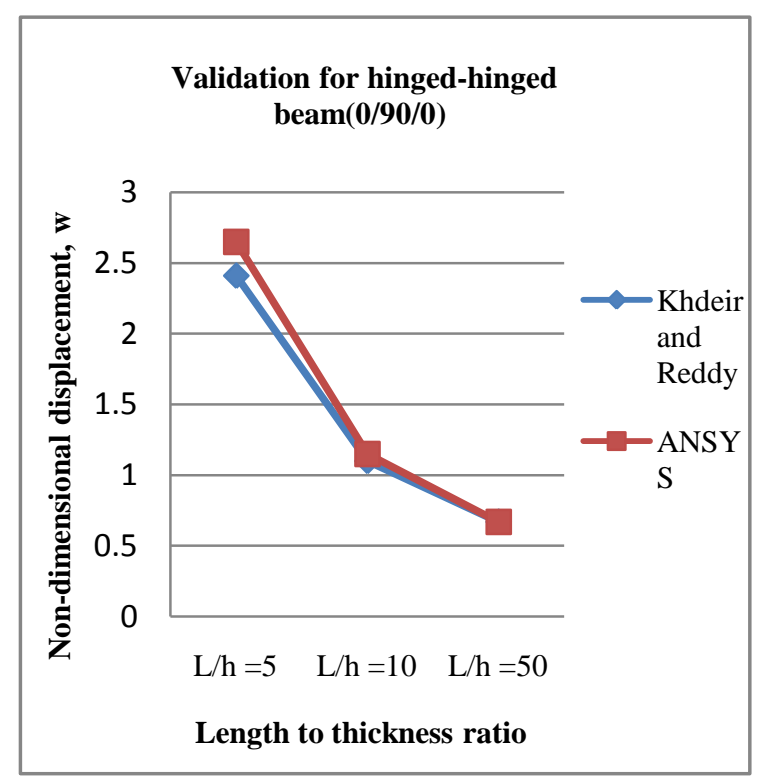

Figure 1: Validation of Non Dimensional Displacement for Hinged-Hinged Beam

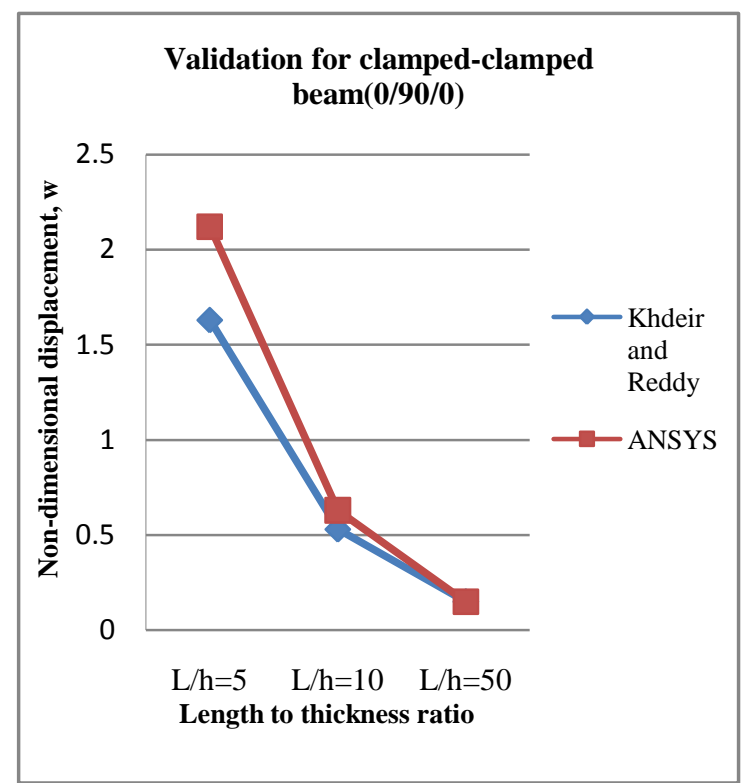

Figure 2: Validation of Non Dimensional Displacement for Clamped-Hinged Beam

\section{B. Observations}

The above results of laminated beam for uniformly distributed load with various boundary conditions.It is seen that values of non dimensional displacement $\mathrm{w}$, decreases with increases in $\mathrm{L} / \mathrm{h}$ ratios and increases with decreases in $\mathrm{L} / \mathrm{h}$ ratios.

\section{Parametric Study}

Parametric study is carried out for various length-tothickness ratios, and different ply orientation and modulus ratio for diffrent boundary conditions.

Table 5: Non-Dimensional Deflection $(\bar{w})$ of Beam (0/90/0) for Various Boundary Conditions

\begin{tabular}{|l|l|l|l|}
\hline \multicolumn{4}{|l|}{$\begin{array}{l}\text { Non-dimensional deflection }(\overline{\mathcal{W}}) \text { of beam (0/90/0) for various } \\
\text { boundary conditions }\end{array}$} \\
\hline$L / h$ & $H-H$ & $C-H$ & $C-C$ \\
\hline 5 & 2.65 & 2.45 & 2.12 \\
\hline 10 & 1.15 & 0.83 & 0.63 \\
\hline 20 & 0.77 & 0.41 & 0.25 \\
\hline 30 & 0.70 & 0.33 & 0.18 \\
\hline 40 & 0.68 & 0.30 & 0.16 \\
\hline 50 & 0.67 & 0.29 & 0.15 \\
\hline
\end{tabular}




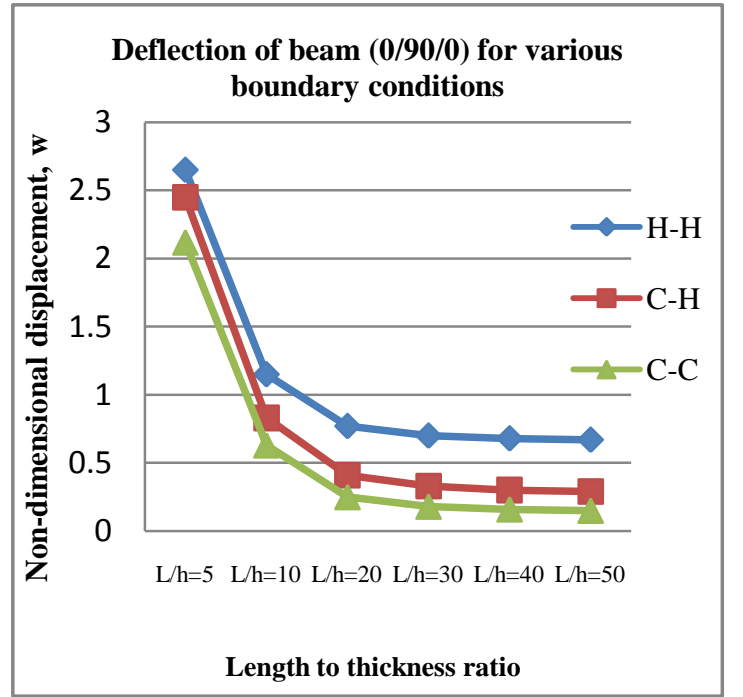

Figure3:Non-Dimensional Deflection $(\bar{w})$ of Beam (0/90/0) for Various Boundary Conditions

Table 6:Non-Dimensional Deflection $(\bar{w})$ of H-H Beam for Different ply Orientation

\begin{tabular}{|l|l|l|l|l|}
\hline \multirow{3}{*}{ X/L } & \multicolumn{4}{|c|}{ Non-dimensional deflection $(\overline{\mathcal{W}})$ for $\mathrm{H}-\mathrm{H}$ beam $(\mathrm{L} / \mathrm{h}=10)$} \\
\cline { 2 - 5 } & 2 LAYERS & 3 LAYERS & 4 LAYERS & 10 LAYERS \\
\hline 0 & 0 & 0 & 0 & 0 \\
\hline 1 & 0.289 & 0.127 & 0.209 & 0.194 \\
\hline 2 & 0.868 & 0.382 & 0.627 & 0.582 \\
\hline 3 & 1.447 & 0.637 & 1.045 & 0.970 \\
\hline 4 & 2.026 & 0.891 & 1.463 & 1.358 \\
\hline 5 & 2.605 & 1.146 & 1.881 & 1.747 \\
\hline 6 & 2.026 & 0.891 & 1.463 & 1.358 \\
\hline 7 & 1.447 & 0.637 & 1.045 & 0.970 \\
\hline 8 & 0.868 & 0.382 & 0.627 & 0.582 \\
\hline 9 & 0.289 & 0.127 & 0.209 & 0.194 \\
\hline 10 & 0 & 0 & 0 & 0 \\
\hline
\end{tabular}

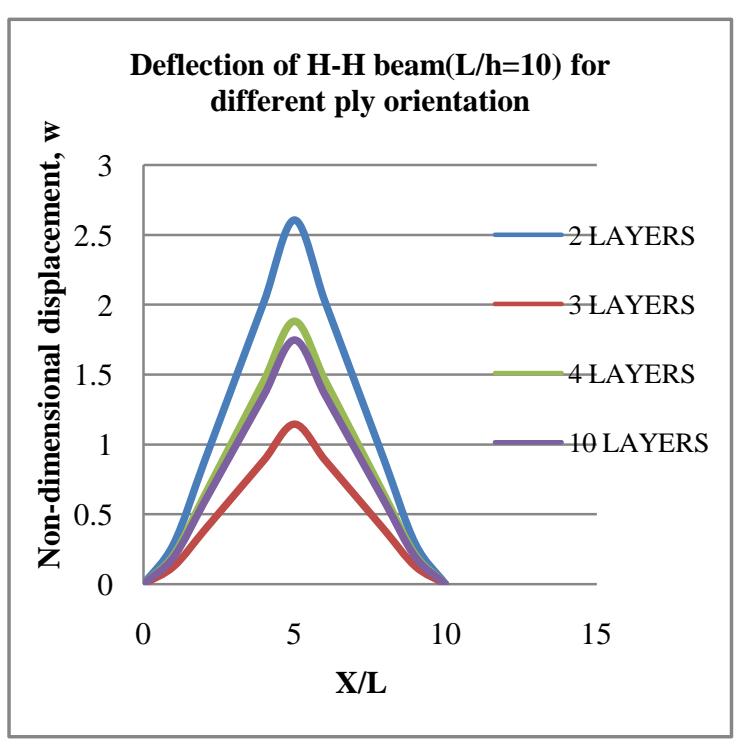

Figure 4:Non-Dimensional Deflection $(\bar{w})$ of H-H Beam for Different ply Orientation
Table 7: Non-Dimensional Deflection $(\bar{w})$ of C-C Beam for Different ply Orientation

\begin{tabular}{|l|l|l|l|l|}
\hline \multirow{3}{*}{ X/L } & \multicolumn{5}{|c|}{ Non-dimensional deflection $(\overline{\mathcal{W}})$ for C-C beam $(\mathrm{L} / \mathrm{h}=10)$} \\
\cline { 2 - 5 } & 2 LAYERS & 3 LAYERS & 4 LAYERS & $\begin{array}{l}10 \\
\text { LAYERS }\end{array}$ \\
\hline 0 & 0 & 0 & 0 & 0 \\
\hline 1 & 0.182 & 0.069 & 0.102 & 0.087 \\
\hline 2 & 0.548 & 0.209 & 0.307 & 0.262 \\
\hline 3 & 0.913 & 0.349 & 0.511 & 0.437 \\
\hline 4 & 1.279 & 0.488 & 0.716 & 0.612 \\
\hline 5 & 1.645 & 0.628 & 0.921 & 0.787 \\
\hline 6 & 1.279 & 0.488 & 0.716 & 0.612 \\
\hline 7 & 0.913 & 0.349 & 0.511 & 0.437 \\
\hline 8 & 0.548 & 0.209 & 0.307 & 0.262 \\
\hline 9 & 0.182 & 0.069 & 0.102 & 0.087 \\
\hline 10 & 0 & 0 & 0 & 0 \\
\hline
\end{tabular}

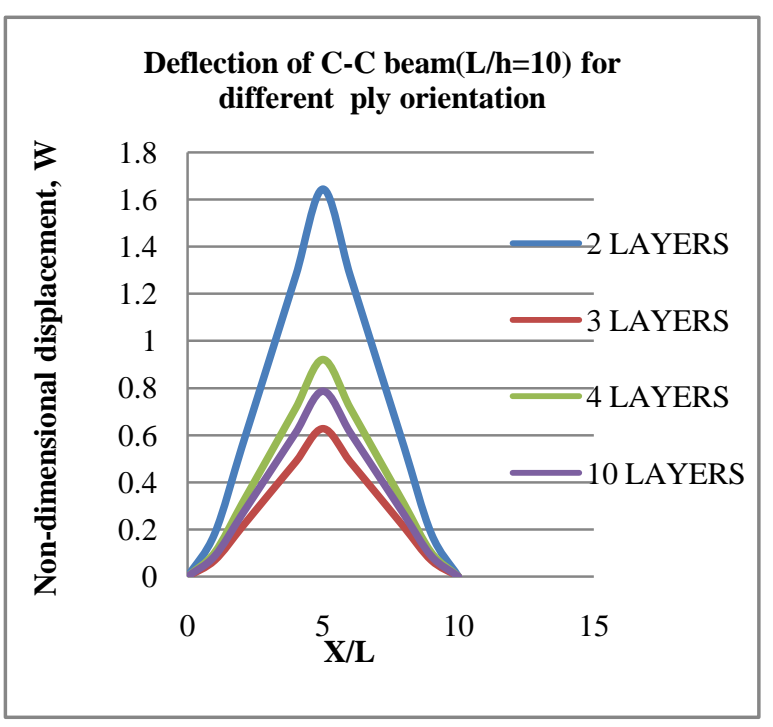

Figure 5: Non-Dimensional Deflection $(\bar{w})$ Of C-C Beam for Different ply Orientantion

Table 8: Effect of Modulus ratio (E1/E2) on Nondimensional Deflection of Beam $(\mathrm{L} / \mathrm{h}=10$ and $0 / 90 / 0)$ for Different Boundary Conditions

\begin{tabular}{|c|c|c|c|}
\hline \multicolumn{5}{|c|}{ Effect of E1/E2 on Non-dimensional deflection, $\bar{w}$} \\
\hline$E_{\sqrt{ }} E_{2}$ & $H-H$ & $C-H$ & $C-C$ \\
\hline 10 & 2.114 & 1.230 & 0.821 \\
\hline 20 & 1.308 & 0.901 & 0.661 \\
\hline 30 & 1.039 & 0.787 & 0.606 \\
\hline 40 & 0.904 & 0.728 & 0.580 \\
\hline 50 & 0.823 & 0.691 & 0.563 \\
\hline
\end{tabular}




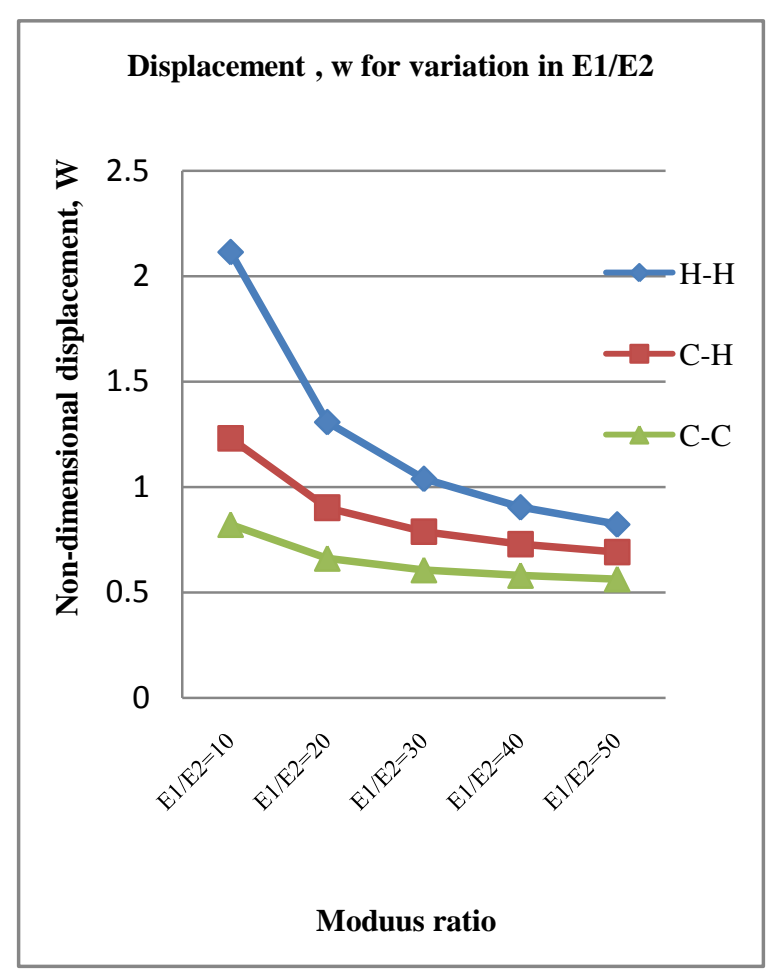

Figure 6: Effect of Modulus ratio (E1/E2) on Non-

Dimensional Deflection of Beam ( $\mathrm{L} / \mathrm{h}=10$ and 0/90/0) for Different Boundary Conditions

\section{CONCLUSION}

In the present work, analysis of laminated composite beam is done using finite element method. Results are first validated with standard results from research papers. Parametric study is done for various length-to-thickness ratios, and different ply orientation for diffrent boundary conditions.

The following conclusions have been drawn:

- It is seen that values of non dimensional displacement $\mathrm{w}$, decreases with increases in $\mathrm{L} / \mathrm{h}$ ratios.

- From fig. 3 it is concluded that for various length to thickness ratio and different boundary conditions deflection is more in simply supported than the clamped condition.

- For symmetric laminate deflection is less than the anti-symmetric laminate.

- From fig.4 and fig.5 two-layer (0/90), three-layer $(0 / 90 / 0)$, four-layer $(0 / 90 / 0 / 90)$ and 10 -layer $(0 / 90 / 0 /$ $90 / . .$.$) lay-ups are considered. It is seen that the$ symmetric cross-ply stacking sequence gives a smaller response than those of antisymmetric ones. In antisymmetric cross-ply arrangements increasing the number of layers for the same thickness will decrease the deflection for all boundary conditions.

- The orthotropicityratio has influence on the deflections, increase in orthotropicity ratio will decrease the deflection.

\section{REFERENCES}

[1] A.A. Khdeir and J.N. Reddy, "An exact solution for the bending of thin and thick cross-ply laminated beams", Computers and structures, Vol.37, Pp.195-203, 1997.

[2] T. Kant and B.S. Manjunath, "Refined theories for composite and sandwich beam with $\mathrm{c}^{\mathrm{o}}$ finite elements", computer and structures, Vol. 33. No. 3, 1989.

[3] D.K. Maiti and P.K. Sinha, "Bending and free vibration analysis of shear deformable laminated composite beams by finite element method",Composite Structures, Vol. 29, No. 4, Pp. 421-431, 1994.

[4] B. Sidda Reddy, A. Ramanjaneya Reddy, J. Suresh Kumar and K. Vijaya Kumar Reddy, "Bending analysis of laminated composite plates using finite element method," International Journal of Engineering, Science and Technology, Vol. 4, No. 2, 2012.

[5] A.A. Khdeir and J.N. Redd, "Free vibration ofcross-ply laminated beams with arbitrary boundaryconditions.” Znt. J. Engng Sci., Vol. 32, Pp. 1971-1980, 1994.

[6] A.A. Khdeir, "A remark on the state-space concept applied to bending, buckling and free vibration of composite laminates." Comput. Struct., Vol. 59, Pp. 813-817, 1996. 